\title{
TRÊS ESPÉCIES NOVAS DE DASINEURA RONDANI (DIPTERA, CECIDOMYIIDAE) ASSOCIADAS A MYRTACEAE NA RESTINGA DA BARRA DE MARICÁ, RIO DE JANEIRO
}

\author{
Valéria Cid Maia ${ }^{1}$
}

\begin{abstract}
Three new SPeCies of Dasineura Rondani (Diptera, Cecidomyinde) associated with Myrtaceae at Restinga da Barra de Marica, Rio de Janeiro. Three new species of Dasineura Rondani, 1840 associated with Eugenia rotundifolia Casar, Myrciaria floribunda (Camb.) Legr. and Neomitranthes obscura (DC.) Legr. (Myrtaceae) are described and illustrated. Some biological informations are provided.

KEY WORDS. Cecidomyiidae, Diptera, galls, Myrtaceae, Restinga da Barra de Maricá
\end{abstract}

A Restinga da Barra de Maricá (Maricá, Rio de Janeiro) é um ambiente com grande riqueza de galhas de Cecidomyiidae, principalmente em Myrtaceae, porém a maioria das espécies causadoras de galhas ainda não foi registrada.

Nesta Restinga foram coletadas sistematicamente, no período de 19861993, ramos de Eugenia rotundifolia Casar, Myrciaria floribunda (Camb.) Legr. e Neomitranthes obscura (DC.) Legr., contendo galhas foliares. Estes foram trazidos para o laboratório de Diptera do Museu Nacional (Universidade Federal do Rio de Janeiro) em sacos plásticos etiquetados. O tratamento dado ao material coletado foi o mesmo descrito em MAIA \& COURI (1993).

Todo os exemplares estudados encontram-se depositados na coleção de Diptera do Museu Nacional do Rio de Janeiro (MNRJ).

\section{Dasineura Rondani, 1840}

Dasineura é o gênero de Cecidomyiidae com maior número de espécies conhecidas, incluindo 110 espécies neárticas (GAGNÉ 1989), e apenas oito neotropicais, duas das quais - D. braziliensis Tavares, 1922 e D. copacabanensis Maia, 1993 registradas no Brasil.

Dasineura compreende formas causadoras de galhas, inquilinas e de vida livre, que se desenvolvem em diversas famílias de plantas.

De acordo com GAGNÉ (1989), o holótipo da espécie-tipo está perdido e Dasineura tornou-se um depositário de gêneros heterogêneos.

1) Departamento de Entomologia. Museu Nacional. Quinta da Boa Vista, São Cristóvão, 20940-040 Rio de Janeiro, Rio de Janeiro, Brasil. Bolsista da CAPES. 
As três espécies de Oligotrophini que se seguem foram incluídas em Dasineura por apresentarem palpo 4-articulado; garras tarsais com um dente desenvolvido; $\mathrm{R}_{5}$ longa, porém mais curta que a asa, encontrando " $\mathrm{C}$ " antes do ápice alar; ovipositor alongado e protrátil; larva: espátula protorácica com dois dentes apicais e haste longa, e segmento terminal com oito papilas terminais cerdosas.

\section{Dasineura globosa, sp.n.}

Figs 1-10

Adulto. Comprimento: 1,32-1,57mm. Cabeça (Fig. 1): Olhos com facetas circulares; antena com 15 flagelômeros com haste longa no macho (Fig. 2), fêmea com 19-21 flagelômeros com haste curta (Fig. 3); flagelômeros ornados como nas figuras 2 e 3. Palpo com quatro artículos cilíndricos e cerdosos. Tórax: Comprimento da asa (a partir do árculo até o ápice): 1,09-1,32mm; nervação como na figura 4. Anepímero com um grupo de cerdas discais, catepisterno e anepisterno nus. Escuto com quatro fileiras de cerdas (duas dorsocentrais e duas laterais). Pernas: garras do tarso com um único dente bem desenvolvido e curva aproximadamente na metade de seu comprimento, empódio tão longo quanto a garra (Fig. 5). Abdômen. Terminália masculina (Fig. 6): gonocoxito amplo, gonóstilo alongado, cerco amplo, com cerdas, e mais longo que o hipoprocto, profundamente separado medialmente formando lobos arredondados; hipoprocto bilobado e cerdoso; edeago alongado, mais longo que o parâmero, afilando gradualmente em direção ao ápice. Ovipositor (Fig. 7): longo, cilíndrico e protrátil com cercos separados, alongados e afilando em direção à extremidade.

Pupa. Comprimento: 1,69-1,82mm. Cabeça (Fig. 8): chifres antenais rudimentares; dente secundário presente na base da cobertura antenal; dois pares de papilas verticais (um par com uma cerda apical com 0,08-0,10mm de comprimento e o outro par nu); região cefálica com um espessamento esclerotinizado na sua margem superior próximo à cobertura de cada antena; face: duas papilas inferiores com cerda e três pares de papilas laterais (dois pares nus e um par cerdoso); espiráculo curto, com 0,04-0,06mm de comprimento; cobertura das asas atingindo o limite dos terços médio e distal do segmento abdominal III; coberturas do primeiro, segundo e terceiro pares de pernas atingindo, respectivamente, o limite das metades proximal e distal do segmento abdominal VI, o limite dos terços proximal e médio do segmento abdominal VII e o limite dos segmentos abdominais VII e VIII. Segmentos abdominais II-VIII cobertos por espinhos diminutos. Ânus em fenda longitudinal. A fase de pupa ocorre no interior da galha.

Galha. Foliar, amarelada e globular, com cerca de 4,0mm de diâmetro quando madura, e com uma única câmara interna (Figs 9, 10).

Holótipo macho. Brasil, Rio de Janeiro: Maricá (Restinga de Barra de Maricá), 13-XI-1986, Valéria Cid Maia leg. (MNRJ). Parátipos: mesmo local de coleta e coletor, dois machos, 13-XI-1986; três machos, 20-IV-1988; um macho, 08-I-1989; um macho, 18-I-1989; um macho, 13-III-1991; dois machos, 23-IX1992; dois machos, 27-IX-1992; um macho, 30-XI-1992; três fêmeas, 13-XI- 


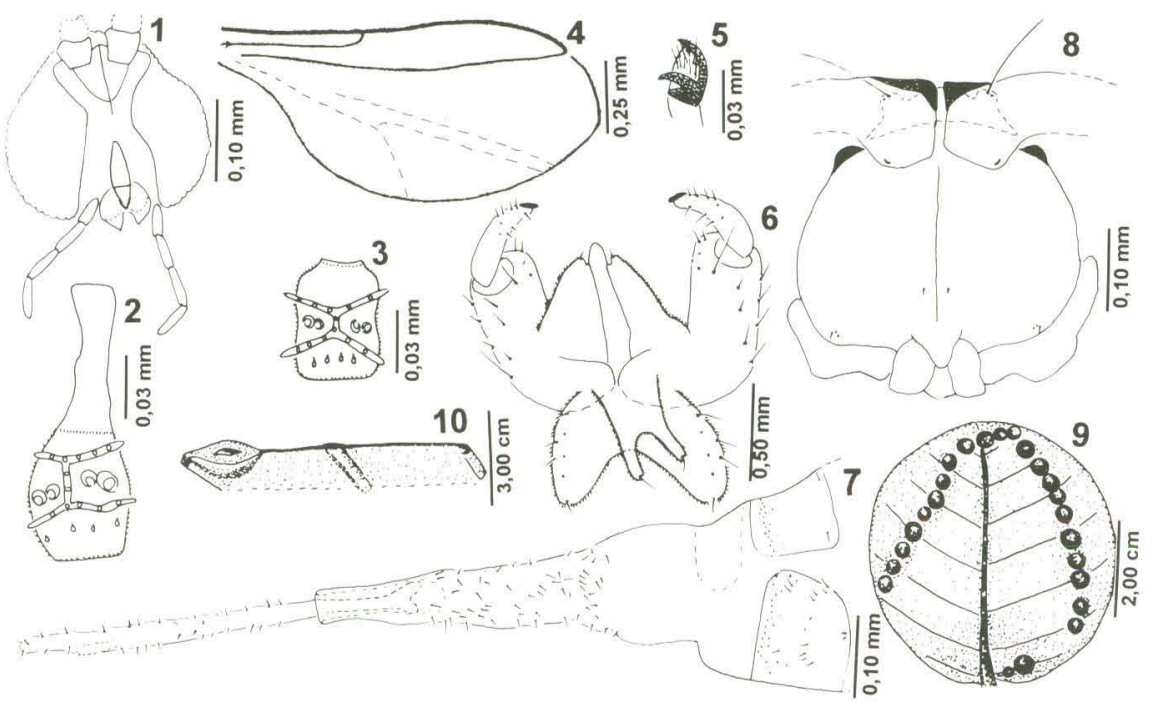

Figs 1-10. Dasineura globosa, sp.n.. (1) Cabeça, macho, vista frontal; (2) flagelômero IV, macho; (3) flagelômero IV, fêmea; (4) asa, macho; (5) garra tarsal e empódio, vista lateral; (6) terminália masculina, vista dorsal; (7) segmento abdominal VIII e ovipositor, vista lateral; (8) cabeça, pupa, vista ventral; (9) galha, aspecto geral; (10) galha, secção transversal.

1986; uma fêmea, 08-I-1987; uma fêmea, 26-VI-1987; uma fêmea, 08-I-1989; três fêmeas, 13-III-1991; três fêmeas, 23-IX-1992; uma fêmea, 30-XI-1992; sete exúvias, 13-III-1991; seis exúvias, 23-IX-1992; uma exúvia, 30-XI-1992 e uma exúvia, 22-VIII-1993. Obtidos de galhas foliares em Eugenia rotundifolia (Myrtaceae).

Larva desconhecida.

Etimologia. O epíteto específico refere-se ao aspecto da galha.

Além de $D$. globosa, outro cecidomí́deo está associado a estas galhas: Resseliella sp., tendo sido obtido apenas na fase larval (15 larvas de terceiro ínstar). Trata-se do primeiro registro deste gênero no Brasil.

\section{Dasineura myrciariae, sp.n.}

Figs 11-22

Adulto. Comprimento: 2,04-2,49mm. Cabeça (Fig. 11): Olhos com facetas circulares. Escapo antenal com 0,85-1,0 vez o seu próprio diâmetro e 1,30-1,54 vezes o comprimento do pedicelo; pedicelo medindo 0,70-1,10 vezes o seu diâmetro; 14 flagelômeros ornados como nas figuras 12 e 13, no macho haste conspícua, na fêmea rudimentar. Palpo com quatro artículos cilíndricos e cerdosos. Labelo com seis cerdas marginais e 9-11 cerdas medianas; hipofaringe setulosa no 
ápice. Tórax: Escuto com quatro fileiras irregulares de cerdas (duas dorsocentrais e duas laterais). Escutelo com um grupo de cerdas medianas na metade proximal; anepímero com um grupo de cerdas discais; anepisterno e catepisterno nus. Asa comprimento (a partir do árculo até o ápice) 1,70-1,92mm, nervação como na figura 14. Garras denteadas, empódio tão longo quanto as garras (Fig. 15).

Abdômen. Terminália masculina (Fig. 16): gonocoxito amplo; gonóstilo afilando gradativamente para o ápice; cerco com cerdas, mais largo que o hipoprocto, com reentrância mediana profunda na margem inferior; hipoprocto cerdoso, bilobado, um pouco mais curto que o edeago; edeago alongado, mais largo na base e terminando em linha quase reta, tendo uma pequena reentrância apical; parâmeros mais curtos que o hipoprocto e subiguais em comprimento aos cercos e mais largos que estes. Ovipositor protrátil e alongado (Fig. 17).

Pupa. Comprimento: 2,16-2,63mm. Cabeça (Fig. 18): chifres antenais rudimentares; dois pares de papilas verticais (um par nu e o outro com cerda apical, com $0,12-0,15 \mathrm{~mm}$ de comprimento); região cefálica com um espessamento esclerotinizado na sua margem superior próximo à cobertura de cada antena; face com duas papilas inferiores com cerdas e três pares de papilas laterais (dois nus e o outro cerdoso). Espiráculo torácico alongado, com 0,13-0,14mm de comprimento. Cobertura da asa atingindo o limite dos terços proximal e médio do segmento abdominal III. Cobertura do primeiro, segundo e terceiro pares de pernas atingindo, respectivamente, o limite das metades proximal e distal do segmento abdominal VI, o limite dos terços proximal e médio do segmento abdominal V e o limite dos terços médio e distal do segmento abdominal IV. Tergitos abdominais II-VIII cobertos por espinhos diminutos. Ânus em fenda longitudinal. A fase de pupa ocorre no interior da galha.

Larva. Coloração: amarela. Comprimento: 2,40-2,80mm.

Espátula protorácica como na figura 19, comprimento: 0,15mm. Segmentos torácicos com seis papilas dorsais cerdosas, dois pares de pleurais com cerda, duas papilas esternais nuas, três pares de laterais externas (dois com cerda e um nu) e três pares de laterais internas (dois com cerda e um nu) e um par de ventrais (nuas no segmento protorácico e cerdosa nos segmentos meso e metatorácico); segmentos abdominais I-VII com seis papilas dorsais com cerda, dois pares de pleurais com cerda, quatro esternais nuas e um par de ventrais com cerda; segmento abdominal VIII com quatro papilas dorsais com cerda, um par de pleurais com cerda e dois pares de ventrais com cerda; segmento terminal (Figs 20, 21) com oito papilas terminais com cerda semelhantes entre si. Ânus em fenda longitudinal. A larva transforma-se em pupa no interior da galha; o adulto emerge através de um orifício pré-construído pela larva.

Holótipo macho. Brasil, Rio de Janeiro: Maricá (Restinga da Barra de Maricá), 27-VIII-1992, Valéria Cid Maia leg. (MNRJ). Parátipos: mesmo coletor e local de coleta, um macho, 27-X-1987; um macho, 22-VI-1992; dois machos, 27-VIII-1992; um macho, 18-IV-1993; duas fêmeas, 27-X-1987; 11 fêmeas, 27-VIII-1992; 18 exúvias, 27-VIII-1992; uma exúvia, 23-X-1992; uma exúvia, 18-IV-1993; uma larva, 28-XII-1992; uma larva, 09-III-1993; duas larvas, 18-III- 


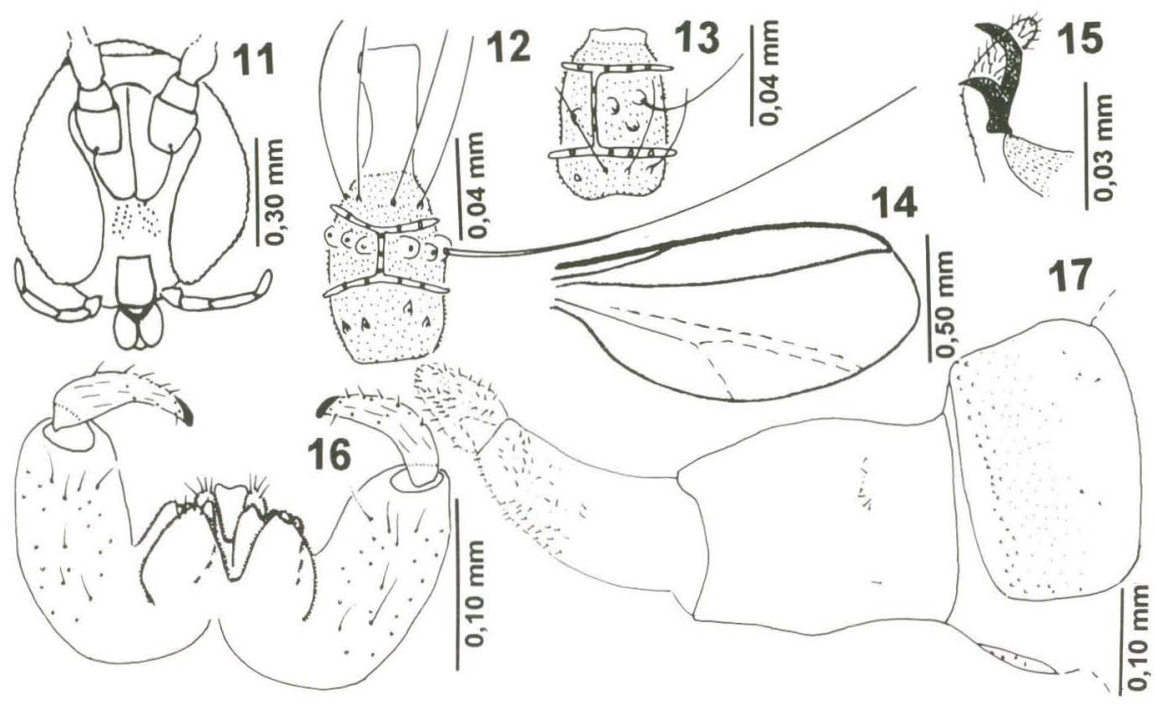

Figs 11-17. Dasineura myrciariae, sp.n.. (11) Cabeça, macho, vista frontal; (12) flagelômero IV, macho; (13) flagelômero IV, fêmea; (14) asa, macho; (15) garra tarsal e empódio, vista lateral; (16) terminália masculina, vista dorsal; (17) segmento abdominal VIII e ovipositor, vista lateral.

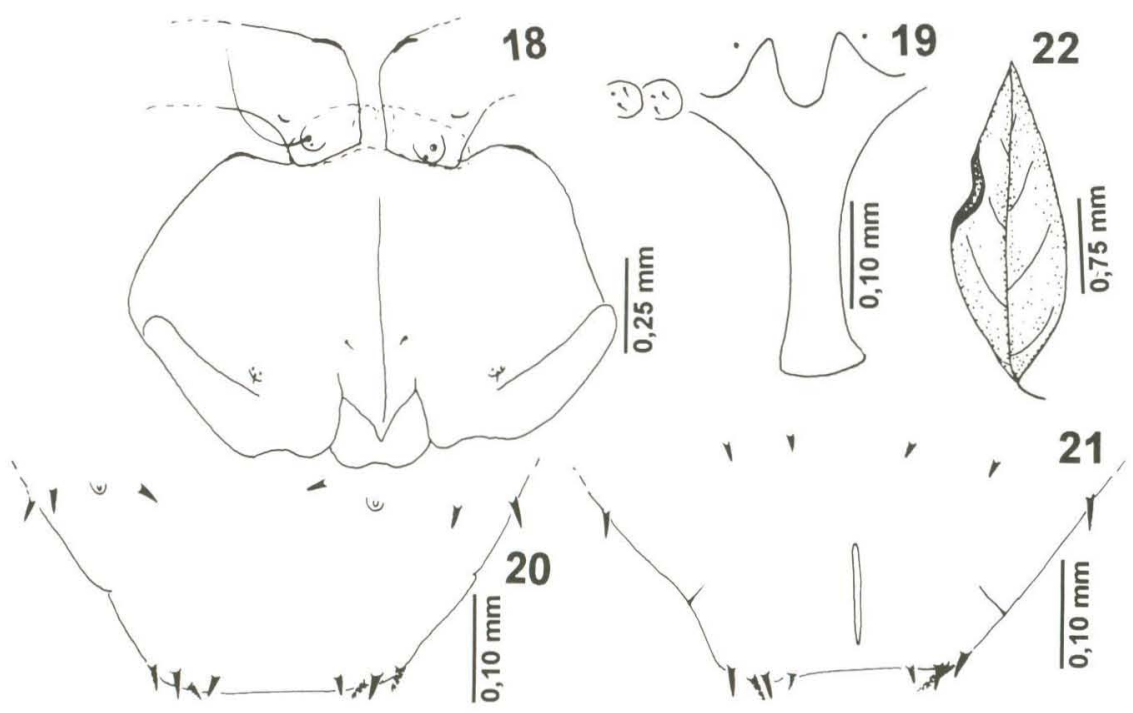

Figs 18-22. Dasineura myrciariae, sp.n.. (18) Cabeça, pupa, vista ventral; (19) espátula protorácica e papilas, larva, vista ventral; (20) segmentos abdominais VIII e terminal, larva, vista dorsal; (21) segmentos abdominais VIII e terminal, larva, vista ventral; (22) galha, aspecto geral. 
1993 e cinco larvas, 18-IV-1993. Obtidos de galhas foliares em Myrciaria floribunda (Myrtaceae).

Galha (Fig. 22): Foliar, formada por um enrolamento da borda da folha. com uma única câmara interna.

Etimologia. O epíteto específico refere-se à planta hospedeira com a qual o cecidomí́deo está associado.

\section{Dasineura tavaresi, sp.n.}

Figs 23-33

Adulto. Comprimento: 2,30-2,45mm. Cabeça (Fig. 23): Olhos com facetas circulares. Antenas: escapo de diâmetro irregular, mais alargado na extremidade superior, com comprimento aproximadamente igual ao seu maior diâmetro e com 1,16 vezes o comprimento do pedicelo; pedicelo arredondado com comprimento aproximadamente igual ao seu diâmetro; 32 flagelômeros curtos e robustos, ornados como na figura 24 ; primeiro e segundo flagelômeros não fundidos; $32^{\circ}$ flagelômero mais longo que os demais. Palpo com quatro artículos cilíndricos, crescentes, todos com cerdas. Labelo com cinco cerdas marginais e quatro medianas. Hipofaringe setulosa no ápice. Tórax - asa: comprimento (a partir do árculo até o ápice) $1,51-1,64 \mathrm{~mm}$; nervação como na figura 25. Escuto com quatro fileiras de cerdas: duas mediodorsais e duas laterais. Anepímero com um grupo de cerdas dorsais; anepisterno e catepisterno nus. Garras tarsais com um dente desenvolvido; empódio aproximadamente do mesmo comprimento que as garras (Fig. 26).

Abdômen. Ovipositor como na figura 27.

Pupa. Comprimento: 2,47-2,74mm. Cabeça (Fig. 28): Chifres antenais conspícuos, dente secundário presente na base de ambas coberturas antenais; região cefálica com um espessamento na margem superior, próximo à base das coberturas antenais; dois pares de papilas verticais (um par nu e o outro com uma cerda apical com 0,15-0,17mm de comprimento - Fig. 29); face com duas papilas inferiores com cerda e três pares de papilas laterais (dois pares nus e um cerdoso). Espiráculo alongado, com 0,10-0,15mm de comprimento. Coberturas da asa, primeiro, segundo e terceiro pares de pernas atingindo, respectivamente, o limite das metades proximal e distal do segmento abdominal III, o limite dos terços médio e distal do segmento abdominal IV, o limite dos terços proximal e médio do segmento abdominal $\mathrm{V}$ e o limite dos terços proximal e distal do segmento abdominal VI. Segmentos abdominais desprovidos de espinhos dorsais. Ânus em fenda longitudinal. A fase de pupa ocorre no interior da galha.

Larva. Coloração amarela. Comprimento: $2,37 \mathrm{~mm}$. Espátula protorácica com $0,13 \mathrm{~mm}$ de comprimento; aspecto geral e papilas como na figura 30 . Segmentos torácicos com três pares de papilas dorsais cerdosas, dois pares de pleurais cerdosas, um par de esternais nuas, três pares de laterais externas (dois com cerda e um nu) e três pares de laterais internas (dois com cerda e um nu) e um par de ventrais (nuas no segmento protorácico e cerdosas no meso e metatórax): 


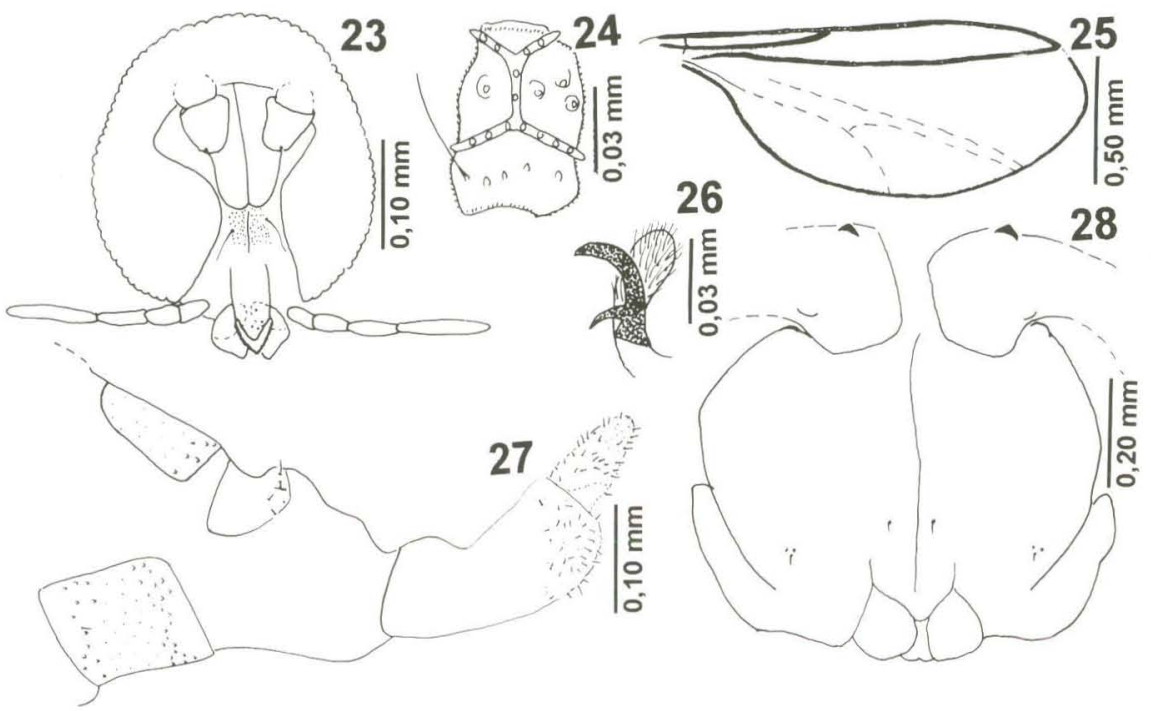

Figs 23-28. Dasineura tavaresi, sp.n.. (23) Cabeça, fêmea, vista frontal; (24) flagelômero IV, fêmea; (25) asa, fêmea; (26) garra tarsal e empódio, vista lateral; (27) segmentos abdominais VII-VIII e ovipositor, vista lateral; (28) cabeça, pupa, vista ventral.
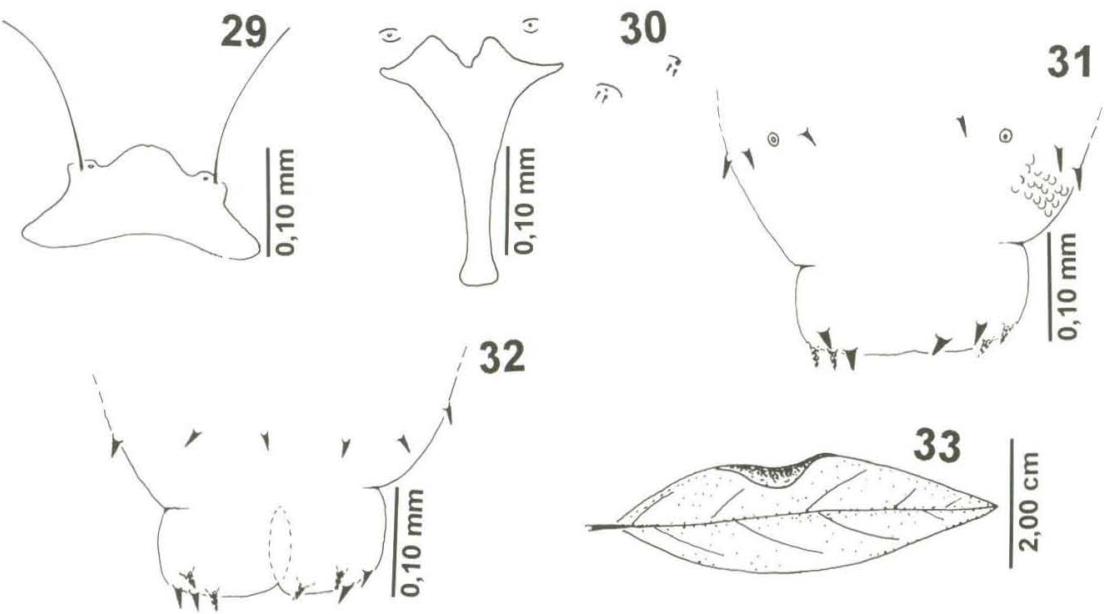

Figs 29-33. Dasineura tavaresi, sp.n.. (29) Papilas verticais, pupa, vista dorsal; (30) espátula protorácica e papilas, larva, vista ventral; (31) segmentos abdominais VIII e terminal, Iarva, vista dorsal; (32) segmentos abdominais VIII e terminal, larva, vista ventral; (33) galha, aspecto geral. 
segmentos abdominais I-VII com dois pares de dorsais e dois pares de pleurais (ambos pares cerdosos), dois pares de esternais nuas e um par de ventrais cerdosas; segmento abdominal VIII (Figs 31, 32) com quatro pares de terminais cerdosas semelhantes entre si. Ânus em fenda longitudinal.

Holótipo fêmea. Brasil, Rio de Janeiro: Maricá (Restinga da Barra de Maricá), 10-IV-1992, Valéria Cid Maia leg. (MNRJ). Parátipos: mesmo coletor e local de coleta, uma fêmea, 17-XII-1987; uma fêmea, 23-X-1987; sete fêmeas, 30-IV-1990; duas fềmeas, 30-V-1990; uma pupa, 30-IV-1990; sete exúvias, 30-IV-1990 e uma larva, 30-IV-1990. Obtidos de galhas foliares em Neomitranthes obscura (Myrtaceae).

Galha (Fig. 33). Verde, unilocular, formada por um enrolamento da borda da folha. Quando madura, apresenta um opérculo para a emergência do adulto.

Macho desconhecido.

Etimologia. O epíteto espécifico é uma homenagem a J. S. Tavares, pesquisador que muito contribui para o conhecimento da cecidologia brasileira.

Nestas galhas, além de $D$. tavaresi, ocorre também uma espécie de Clinodiplosini, obtida apenas na fase larval (30 larvas de terceiro ínstar).

AGRADECIMENTOS. Ao Sr. Atidio Manhães (Departamento de Botânica. Universidade Federal do Rio de Janeiros pelos desenhos das galhas ea Dra. Márcia Souto Couri (Museu Nacional) pela leitura crítica.

\section{REFERÊNCIAS BIBLIOGRÁFICAS}

Gagne, R.J. 1989. The Plant-Feeding Gall Midges of North America. Ithaca, Comstock Cornell University Press, 356p.

MaiA, V.C. \& M.S. Couri. 1993. Descrição de três espécies novas de Bruggmannia Tavares, 1906 (Diptera, Cecidomyiidae, Asphondyliidi) do Brasil associadas com Guapira opposita (Nyctaginaceae). Rev. Brasil. Biol. 53 (2): 209-215. 